\title{
Selection of Effective Control factors for TMT Bars using Taguchi
}

\author{
B. Vijaya Prakash, S. Sundarapandian
}

\begin{abstract}
Temp Core based technology was used in the production of thermo mechanically treated bars for higher yield strength. The Process involves rapid cooling of hot bars by passing the bars through a series of water jets after they are rolled through the finishing stand. One of the important quality parameter for the TMT bars is Yield strength. This Yield strength mainly depends upon various factors. The objective of this research is to select the optimal combination of the factors which will ensure the required yield strength and also to find out the contribution of each factor in the improvement of yield strength. In this research work, experimental readings were taken from the plant and it was analyzed by Taguchi Method to find out the optimum combination factors using MINITAB software. The Orthogonal Array (OA), Signal-to-Noise ratio ( $S / N$ ratio) and Analysis of Variance (ANOVA) were employed to optimize the process parameters. With the help of graphs optimum parameter values were obtained and the confirmation experiments were carried out.
\end{abstract}

Keywords: TMT, Yield Strength, Design of Experiments, Orthogonal Array, S/N Ratio, Taguchi Method.

\section{INTRODUCTION}

Unprocessed iron rods and concrete slabs were used in olden days for buildings and homes. The problem with this process was the rods would begin to rust away much earlier than expected. This, in turn, affects the stability of the structures in the long run, making them unsafe, unreliable, prone to frequent repairs, leakage due to rains and general dissatisfaction of the owner. Thermo Mechanically Treated (TMT) bars are the solution for all the above mentioned problems. They are made according to universal standards of strength, rigidity and flexibility. The TMT bars are produced in various grades to suit the application. The yield strength of the TMT bars are based on the input process parameters like rolling temperature, rolling speed, water pressure and diameter of the nozzle. The objective of this research is to select the optimal combination of the factors which will ensure the required yield strength and also to find out the contribution of each factor in the improvement of yield strength. Here an attempt has been made to conduct Design of Experiments (DOE) by Taguchi Method to select a set of optimal combination of process parameters for the optimum value of yield strength of TMT bars. Taguchi method involves the development of designs for studying the variation. Taguchi Methodis one of the statistical methods developed by Taguchi and Konishi (1987). This method is used in many fields of Engineering in addition to

\footnotetext{
Revised Manuscript Received on 14 August, 2019.

B. Vijaya Prakash, Assistant Professor, Dept. Mechanical Engineering, Sri Shakthi Institute of Engineering and Technology, Coimbatore, Tamil Nadu, India. (E-mail id:vijaiprakash76@gmail.com)

Dr. S.Sundarapandian, Professor, Dept. Automobile Engineering, Easwari Engineering College, (SRM Group of Institutions), Chennai, Tamil
} Nadu, India. finding out the quality of manufacturing goods. The selection of control factors should have the ability to nullify the noise factors. Orthogonal Arrays (OA) are used to conduct a set of experiments. Achieving the desired results depends on selection and grouping of process parameters into control or signal and noise factors.

\section{TMT PROCESS}

Thermo mechanically treated bars is the technological advancement for the production of high strength deformed steel bars for concrete reinforcement. In this process higher strength is obtained by thermo mechanical treatment, wherein the steel bars get intensive cooling immediately after rolling. Sudden reduction in temperature creates a hardened surface layer with internal core still being hot. While further cooling in atmosphere, tempering takes place by the heat from the core. This process is expected to improve the properties of strength and ductility in the bar. TMT bars have an optimum combination of strength, ductility, bend ability and other desirable properties. The consumption of TMT bars are less than half of the mild steel bars aver Roy and Sandhwar (2015). TMT bars can have high resistance to seismic (earth quake prone) loads due to its higher UTS/YS ratio. If Fe415 rebar is replaced by Fe500 rebar the total saving in consumption of steel is about 10-25 percent. Proper control of final quenching temperature leads optimum strength with high UTS/YS ratio describe Gaur et al. (2018). Roy and Ranjit (2001) state that the basic requirements of rebars today are low cost deformed bars with yield strength of $500 \mathrm{~N} / \mathrm{mm}^{2}$ with adequate ductility for the seismic zones. Nearly about 55 to 60 per cent of India falls under the seismic zone.

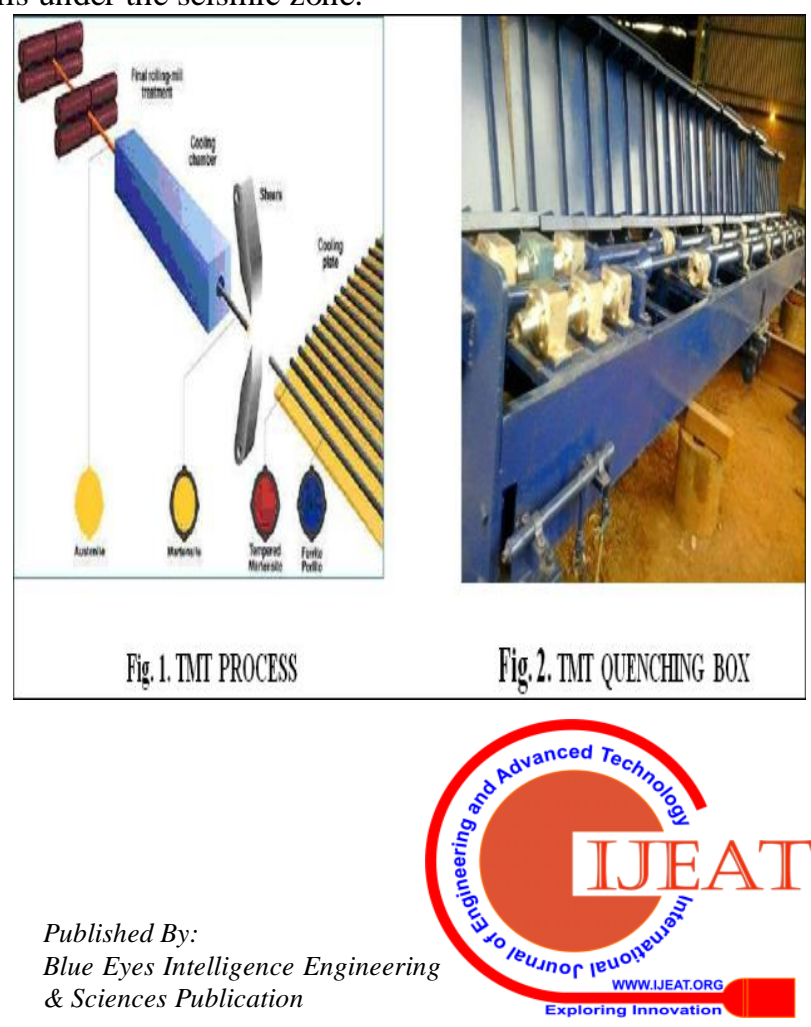


In the TMT process (Fig.1) when the rebar undergoes apid cooling while it passes through quenching box (Fig.2), the temperature gradient developed causes the heat to flow from the center to the surface. This causes self-tempering of the martensite structure of the rebar, due to the heat left in the core at the end of this stage. Further slow cooling of rebar in the cooling bed makes the austenitic core transforms into ferrite and pearlite or into bainite, ferrite and pearlite view Ravi Kumar et al. (2015). According to Edwin and Dean (2002) this process increases the yield strength of about 150 to 250 Mpa depending on cooling conditions.

\section{METHODOLOGY}

This research work aims to find out optimal process or control parameters to improve the yield strength of TMT bars. The process or control parameters selected in this research work are bar temperature $(\mathrm{Tb})$, rolling speed $(\mathrm{S})$, water pressure $(\mathrm{P})$, water flow rate $(\mathrm{Q})$, quenching water temperature (Tw) and quenching time $(\mathrm{t})$. This work involves experimental reading in the plant for different combinations of control parameters and taking the yield strength for the above combinations. The yield strength of the TMT bar should satisfy the value specified by IS 1786:2008. There are various sizes of TMT bars with different grades. The Mechanical properties prescribed by IS 1786:2008 is shown in Table 1. The various sizes of TMT bars is given in Table 2 .

Table 1: Mechanical Properties Of Tmt Bars

\begin{tabular}{|c|c|c|}
\hline SI.No. & MECHANICAL PROPERTIES (min.) & Fe500 \\
\hline 1 & Yield Stress (N/mm2) & 500 \\
\hline 2 & Tensile Strength (N/mm2) & 545 \\
\hline 3 & Elongation & $12.5 \%$ \\
\hline
\end{tabular}

Table 2: Sizes Of Tmt Bars

VARTOUS DIANETERS OF TNT BARS $6 \mathrm{~mm}, 8 \mathrm{~mm}, 10 \mathrm{~mm}, 12 \mathrm{~mm}, 16 \mathrm{~mm}, 20 \mathrm{~mm}, 25 \mathrm{~mm}, 32 \mathrm{~mm}$

In this research TMT bar of $12 \mathrm{~mm}$ diameter and Fe500 grade is selected. Fe500 grade TMT bars are having minimum yield strength of $545 \mathrm{~N} / \mathrm{mm}^{2}$ as per IS 1786:2008 standard. In this research it is necessary to ensure minimum yield strength of $545 \mathrm{~N} / \mathrm{mm}^{2}$. This can be achieved by conducting Design of Experiments (DOE) for the various combinations of control parameters.

\subsection{Design Of Experiments}

Design of Experiments is a statistical approach that allows for multiple input factors to be manipulated, determining their effect on a desired output. The major approaches of DOE are factorial design, response surface, mixture design and taguchi design. In this study, Design of Experiment was conducted using MINITAB 17 software. Out of these approaches this research focuses on Taguchi Method.

\subsection{Taguchi Method}

When the number of factors increases, the problem becomes very complex and laborious under the factorial design method state SrinivasAthreya and Venkatesh (2012).
Hence a statistical method Taguchi was used by the investigator. To overcome this situation, Taguchi suggested orthogonal array method to study all the parameters with minimum number of experiments to be conducted. This method employs the use of loss function to identify and account the performance measures that are deviating from the target value. The value of this loss function is converted into signal-to-noise (S/N) ratio. As of August 26, 2000, the IITB-EE listed on its website that there are three types of performance measures namely: nominal-the-best, larger-thebetter and smaller-the-better. In this research work largerthe-better is selected as the aim is to increase the yield strength of TMT bar.

\subsection{Steps Involved In Taguchi Method}

Taguchi's parameter design involves the following steps:

Identify the main function, side effects and failure mode.

Identify the noise factors, testing conditions and quality characteristics.

Identify the objective function to be optimized.

Identify the control factors and their levels.

Select the Orthogonal Array and the matrix.

Conduct the matrix experiment.

Analyze the data: Predict the optimum levels and performance.

Perform the verification experiment.

\subsection{Identification Of Main Function And Its Side} Effects

Main Function: Production of Thermomechanically Treated bars

Side effects : Variation in yield strength.

The various control and noise factors that influence the Tensile strength of TMT bars are shown in Table 3 .

Table 3: Factors Affecting Tensile Strength Of Tmt Bars

\begin{tabular}{|l|l|l|}
\hline $\begin{array}{l}\text { SI.N } \\
\text { o. }\end{array}$ & CONTROL FACTORS & $\begin{array}{l}\text { NOISE } \\
\text { FACTORS }\end{array}$ \\
\hline 1 & Bar Temperature, Tb in ${ }^{\circ} \mathrm{C}$ & Fuel \\
\hline 2 & Rolling Speed, S in mps & $\begin{array}{l}\text { Energy } \\
\text { fluctuations }\end{array}$ \\
\hline 3 & Water Pressure, P in bar & Type of Pump \\
\hline 4 & $\begin{array}{l}\text { Water Flow Rate, Q in } \\
\mathrm{m}^{3} / \mathrm{hr} .\end{array}$ & Pipe condition \\
\hline 5 & $\begin{array}{l}\text { Quenching Water } \\
\text { Temperature, Tw in }{ }^{\circ} \mathrm{C}\end{array}$ & Cooling effect \\
\hline 6 & Quenching Time, $\mathrm{t}$ in sec & Machine condition \\
\hline
\end{tabular}

Out of the above factors, decision about the factors has to be taken to decide the control factors which significantly affect the yield strength of the bar. Remaining factors are considered as noise factors.

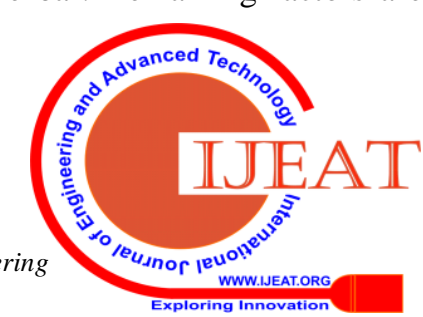




\subsection{Identifying The Testing Conditions And Quality} Characteristics

Quality Characteristic: yield strength

Testing Equipment : Universal Testing Machine

Bar size $\quad: 12 \mathrm{~mm}$ dia.

\subsection{Identifying The Objective Function}

In this research, the $\mathrm{S} / \mathrm{N}$ ratio for higher-the-better quality characteristic on the tensile strength error of the bar is chosen to get optimum yield strength with minimum error. The $\eta$ value of the $S / N$ ratio is computed based on

$\mathrm{n}$

$\eta \quad=-10 \log 10\left(1 / \mathrm{r} \Sigma\left(1 / \mathrm{yi}^{2}\right)\right)$.

Where $r$ is the sample size and yi is the measured yield strength error value.

\subsection{Identifying Control Factors And Their Levels}

The control factors were identified based on trial and run method in the plant and their levels is shown in Table 4.

Table 4: Control Factors And Their Levels

\begin{tabular}{|c|l|c|c|c|}
\hline \multirow{2}{*}{$\begin{array}{c}\text { SI.N } \\
\mathbf{0}\end{array}$} & \multicolumn{1}{|c|}{$\begin{array}{c}\text { CONTROL } \\
\text { FACTORS }\end{array}$} & \multicolumn{3}{|c|}{ LEV } \\
\cline { 3 - 5 } & \multicolumn{1}{|c|}{ ELS } \\
\hline 1 & Bar Temperature, $\mathrm{T}_{\mathrm{b}}$ in ${ }^{\circ} \mathrm{C}$ & $\begin{array}{c}100 \\
0\end{array}$ & 1025 & 1050 \\
\hline 2 & Rolling Speed, S in mps & 6.5 & 7.5 & 8.5 \\
\hline 3 & Water Pressure, $\mathrm{P}$ in bar & 7 & 8 & 9 \\
\hline 4 & $\begin{array}{l}\text { Water Flow Rate, } \mathrm{Q} \text { in } \\
\mathrm{m}^{3} / \mathrm{hr}\end{array}$ & 250 & 275 & 300 \\
\hline 5 & $\begin{array}{l}\text { Quenching Water } \\
\text { Temperature, } \mathrm{T}_{\mathrm{w}} \text { in }{ }^{\circ} \mathrm{C}\end{array}$ & 28 & 30 & 32 \\
\hline 6 & Quenching Time, $\mathrm{t}$ in sec & 0.8 & 1.0 & 1.2 \\
\hline
\end{tabular}

\subsection{Selection Of Orthogonal Array}

L27 orthogonal array is used for the study as suggested by Babu and Reddy (2017). Up to thirteen factors can be used in L27 orthogonal array and also the number of experiments to be conducted is twenty seven. In this research as the number of factors used are six and there may be chance for including the factors further in future work, it is decided to select L27 orthogonal array.

\subsection{Conducting The Matrix Experiment}

The experiments were conducted with the control factors and their set levels as shown in Table 4 as in L27 orthogonal array. The experimental layout with selected values of factors along with their levels is shown in Table 5. Each of the above twenty seven experiments was conducted five times to account for the variations that may occur due to the noise factors. The yield strength was measured using the Universal Testing Machine. The measured values of yield strength obtained from different experiments are also shown in Table 5. The $\mathrm{S} / \mathrm{N}$ ratio of higher-the-better type is selected and the $\mathrm{S} / \mathrm{N}$ ratio for yield strength variations are calculated and shown in Table 5. The optimum values obtained from Table 5 based on higher $\mathrm{S} / \mathrm{N}$ ratio fromcontrol parameters and their levels are selected and shown in Table 6.

Table 5: Yield Strength Variation Measured For 12mm Tmt Bar With S/N Ratio

\begin{tabular}{|c|c|c|c|c|c|c|c|c|c|c|c|c|c|}
\hline \multirow{3}{*}{$\begin{array}{r}\text { Trial } \\
\text { No }\end{array}$} & \multicolumn{6}{|c|}{ CONTROL FACTORS } & \multicolumn{6}{|c|}{ YIELD STRENGTH, Mpa } & \multirow{3}{*}{ S/N Ratio } \\
\hline & & & & & & & \multicolumn{6}{|c|}{ READINGS TAKEN } & \\
\hline & $\mathbf{T}_{\mathbf{b}}$ & $\mathbf{S}$ & $\mathbf{P}$ & $\mathbf{Q}$ & $\mathbf{T}_{\mathbf{w}}$ & t & 1 & 2 & 3 & 4 & 5 & Mean & \\
\hline 1 & 1 & 1 & 1 & 1 & 1 & 1 & 524 & 532 & 534 & 528 & 532 & 530.0 & 54.4855 \\
\hline 2 & 1 & 1 & 1 & 1 & 2 & 2 & 535 & 537 & 539 & 538 & 534 & 536.6 & 54.5930 \\
\hline 3 & 1 & 1 & 1 & 1 & 3 & 3 & 541 & 544 & 542 & 541 & 542 & 542.0 & 54.6800 \\
\hline 4 & 1 & 2 & 2 & 2 & 1 & 1 & 536 & 539 & 540 & 548 & 547 & 542.0 & 54.6800 \\
\hline
\end{tabular}




\begin{tabular}{|c|c|c|c|c|c|c|c|c|c|c|c|c|c|}
\hline 5 & 1 & 2 & 2 & 2 & 2 & 2 & 525 & 527 & 528 & 536 & 538 & 530.8 & 54.4986 \\
\hline 6 & 1 & 2 & 2 & 2 & 3 & 3 & 523 & 522 & 526 & 530 & 529 & 526.0 & 54.4197 \\
\hline 7 & 1 & 3 & 3 & 3 & 1 & 1 & 529 & 528 & 530 & 532 & 539 & 531.6 & 54.5117 \\
\hline 8 & 1 & 3 & 3 & 3 & 2 & 2 & 530 & 531 & 521 & 532 & 536 & 530.0 & 54.4855 \\
\hline 9 & 1 & 3 & 3 & 3 & 3 & 3 & 538 & 526 & 529 & 528 & 534 & 531.0 & 54.5019 \\
\hline 10 & 2 & 1 & 2 & 3 & 1 & 2 & 541 & 541 & 538 & 536 & 535 & 538.2 & 54.6189 \\
\hline 11 & 2 & 1 & 2 & 3 & 2 & 3 & 556 & 552 & 555 & 557 & 556 & 555.2 & 54.8890 \\
\hline 12 & 2 & 1 & 2 & 3 & 3 & 1 & 548 & 547 & 549 & 550 & 552 & 549.2 & 54.7946 \\
\hline 13 & 2 & 2 & 3 & 1 & 1 & 2 & 546 & 545 & 548 & 548 & 550 & 547.4 & 54.7661 \\
\hline 14 & 2 & 2 & 3 & 1 & 2 & 3 & 548 & 549 & 547 & 548 & 552 & 548.8 & 54.7883 \\
\hline 15 & 2 & 2 & 3 & 1 & 3 & 1 & 545 & 546 & 549 & 549 & 551 & 548.0 & 54.7756 \\
\hline 16 & 2 & 3 & 1 & 2 & 1 & 2 & 549 & 550 & 558 & 552 & 552 & 552.2 & 54.8419 \\
\hline 17 & 2 & 3 & 1 & 2 & 2 & 3 & 535 & 539 & 543 & 547 & 549 & 542.6 & 54.6896 \\
\hline 18 & 2 & 3 & 1 & 2 & 3 & 1 & 543 & 544 & 549 & 548 & 547 & 546.2 & 54.7470 \\
\hline 19 & 3 & 1 & 3 & 2 & 1 & 3 & 550 & 548 & 550 & 542 & 542 & 546.4 & 54.7502 \\
\hline 20 & 3 & 1 & 3 & 2 & 2 & 1 & 555 & 552 & 558 & 565 & 566 & 559.2 & 54.9513 \\
\hline 21 & 3 & 1 & 3 & 2 & 3 & 2 & 556 & 553 & 556 & 562 & 562 & 557.8 & 54.9296 \\
\hline 22 & 3 & 2 & 1 & 3 & 1 & 3 & 554 & 554 & 557 & 561 & 563 & 557.8 & 54.9296 \\
\hline 23 & 3 & 2 & 1 & 3 & 2 & 1 & 559 & 557 & 559 & 558 & 562 & 559.0 & 54.9482 \\
\hline 24 & 3 & 2 & 1 & 3 & 3 & 2 & 562 & 561 & 562 & 563 & 565 & 562.6 & 54.9978 \\
\hline 25 & 3 & 3 & 2 & 1 & 1 & 3 & 565 & 563 & 564 & 562 & 562 & 563.2 & 55.0133 \\
\hline 26 & 3 & 3 & 2 & 1 & 2 & 1 & 555 & 562 & 563 & 562 & 552 & 558.8 & 54.9451 \\
\hline 27 & 3 & 3 & 2 & 1 & 3 & 2 & 562 & 564 & 564 & 561 & 558 & 561.8 & 54.9916 \\
\hline
\end{tabular}

Table 6:Optimum Values Of Control Parameters

\begin{tabular}{|c|c|c|}
\hline SI.No. & CONTROL FACTOR & OPTIMUM VALUE \\
\hline 1 & Bar Temperature, $\mathrm{Tb}$ in ${ }^{\circ} \mathrm{C}$ & 1050 \\
\hline 2 & Rolling Speed, $\mathrm{S}$ in mps & 8.5 \\
\hline
\end{tabular}




\begin{tabular}{|c|c|c|}
\hline 3 & Water Pressure, $\mathrm{P}$ in bar & 8 \\
\hline 4 & Water Flow Rate, $\mathrm{Q}$ in $\mathrm{m}^{3} / \mathrm{hr}$. & 250 \\
\hline 5 & Quenching Water Temperature $\mathrm{Tw}$ in ${ }^{\circ} \mathrm{C}$ & 28 \\
\hline 6 & Quenching Time, $\mathrm{t}$ in sec & 1.2
\end{tabular}

\subsection{Confirmation Experiment}

Five sets of confirmation experiments were conducted for the study by selecting the optimum values of control parameters from Table 6 . Keeping the optimum values of control factors obtained for bar temperature $1050 \mathrm{C}$, rolling speed $8.5 \mathrm{~m} / \mathrm{sec}$, water pressure 8 bar, water flow rate 250 $\mathrm{m}^{3} / \mathrm{hr}$., quenching water temperature $28^{\circ} \mathrm{C}$ and quenching time 1.2 seconds and their yield strength values were checked. The confirmation experiment results obtained is tabulated in Table 8 under results and discussion.

\section{RESULTS AND DISCUSSION}

Six control factors that are predominantly influencing the yield strength of the bar were selected and the experimental data was taken and tabulated as shown in Table 5. Five readings were taken at different combinations of control factors and the mean value of yield strength was calculated. Taguchi method which is one of the approaches of design of experiments (DOE) was selected for the research work. L27 orthogonal array was chosen and $\mathrm{S} / \mathrm{N}$ ratio for variation of yield strength was found and tabulated as shown in Table 5. A graph was plotted with all the control factors vs. S/N ratio as shown in Fig. 3 to find the influence of control factors on yield strength.

\subsection{Analysis Of Data}

The influence of control factors on the Yield strength is shown in Fig. 3

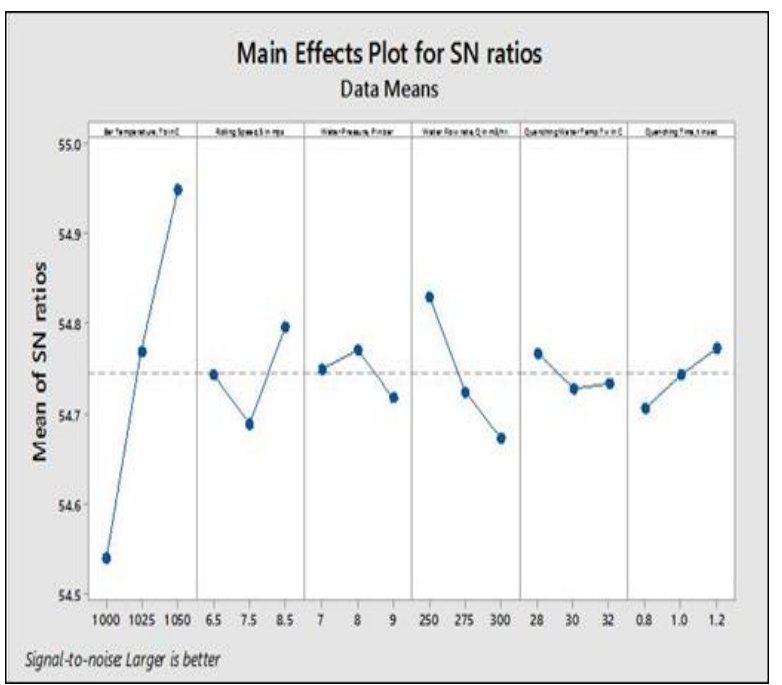

Fig. 3. INFLUENCE OF CONTROL FACTORS

The graph shown in Fig.3 depicts the control parameters for various $\mathrm{S} / \mathrm{N}$ ratios to find the optimum yield strength of the bar. From the graph shown in Fig. 3 and data in Table.5 the optimum value of yield strength was found as 563.2 $\mathrm{N} / \mathrm{mm}^{2}$ for which the control factors are bar temperature $1050^{\circ} \mathrm{C}$, rolling speed $8.5 \mathrm{~m} / \mathrm{sec}$, water pressure 8 bar, water Flow rate $250 \mathrm{~m}^{3} / \mathrm{hr}$., quenching water temperature $28^{\circ} \mathrm{C}$ and quenching time 1.2 seconds. The same was tabulated in Table 6. The Analysis of Variance for yield strength variation with respect to $\mathrm{S} / \mathrm{N}$ ratio is depicted in Table 7 .

Table 7: Anova For Yield Strength Variation (S/N Ratio)

\begin{tabular}{|c|c|c|c|c|c|}
\hline $\mathbf{8}$ & $\mathbf{D O F}$ & Sum of Squares & Mean Square & F Value & Contribution \\
\hline$(\mathbf{p})$ & $\mathbf{( D F p )}$ & $\mathbf{( S S p )}$ & $\mathbf{( V p )}$ & $\mathbf{( F p )}$ & $(\mathbf{Q p})$ \\
\hline $\mathrm{Tb}$ & 2 & 0.7251 & 0.3626 & 39.50 & $93.7 \%$ \\
\hline $\mathrm{S}$ & 2 & 0.0007 & 0.0004 & 0.04 & $0.09 \%$ \\
\hline $\mathrm{P}$ & 2 & 0.0134 & 0.0066 & 0.73 & $1.73 \%$ \\
\hline $\mathrm{Q}$ & 2 & 0.0163 & 0.0082 & 0.89 & $2.1 \%$ \\
\hline $\mathrm{Tw}$ & 2 & 0.0036 & 0.0018 & 0.20 & $0.4 \%$ \\
\hline $\mathrm{t}$ & 2 & 0.0018 & 0.0009 & 0.10 & $0.23 \%$ \\
\hline Error & 14 & 0.1285 & 0.0092 & & \\
\hline Total & 26 & 0.7738 & & & \\
\hline
\end{tabular}


The Analysis of variance from Table 7 depicts the contribution of each control factors towards the optimum value of yield strength. This analysis finds the bar temperature $(\mathrm{Tb})$ highly influencing the yield strength of the bar. Hence by properly maintaining the bar temperature high yield strength of the bar can be obtained.

\subsection{Confirmation Result}

Five sets of confirmation experiments were conducted by selecting the optimum values taken from Table 6 and the yield strength values were checked and results obtained are tabulated in Table 8.

Table 8: Confirmation Experiment Result

\begin{tabular}{|c|c|}
\hline Experiment No. & Yield Strength, N/mm \\
\hline 1 & 562 \\
\hline 2 & 563 \\
\hline 3 & 562 \\
\hline 4 & 564 \\
\hline 5 & 565 \\
\hline Mean & 563.2 \\
\hline
\end{tabular}

From Table 8 it was noted that the yield strength values obtained proved to be consistent. This in turn ensures the contribution of optimal combination of control parameters improves the yield strength.

\section{CONCLUSION}

This paper illustrates the application of Taguchi method in the optimization of yield strength of $12 \mathrm{~mm}$ TMT bar of Fe500 grade. The following conclusions can be drawn based on the above experimental results:

Among the six process parameters chosen, the bar temperature $(\mathrm{Tb})$ is having significant effect on the improvement of yield strength which is the quality characteristic and the contribution of bar temperature $\mathrm{Tb}$ is about ninety four per cent

This shows that final yield strength of the bar is greatly affected by bar temperature.

The optimum levels of process parameters are found to be bar temperature $1050^{\circ} \mathrm{C}$, rolling speed $8.5 \mathrm{~m} / \mathrm{sec}$, water pressure $8 \mathrm{bar}$, water flow rate $250 \mathrm{~m}^{3} / \mathrm{hr}$., quenching water temperature $28^{\circ} \mathrm{C}$ and quenching time 1.2 seconds.

For getting higher yield strength of the bar care should be taken to maintain the bar temperature at $1050^{\circ} \mathrm{C}$.

\section{REFERENCES}

1. Babu, R.G., and Reddy, D.A. 2017. "Use of L27 Orthogonal Array With Grey Taguchi Technique to Optimize MRR and SR in EDM Machining for AI-6082, AI-6061, AI-2014 and Mild Steel”, International Journal of Engineering Research and Application, Vol. 7, No.11, pp. 11-21, doi:10.9790/9622-0711411212.

2. Edwin, R.U., and Dean, B. 2004. "Taguchi Approach to Design Optimization for Quality and Cost", An Overview in Proc. Conference of the International Society of Parametric Analysis, NASA Langley Research Center, Hampton, VA, United States, January 38-57.

3. Gaur, A., Dutta, J., Barkar, M., and Lakshminarasimhan, B. 2018. "Development of Fe500s Earth quake resistance TMT Rebar", International Journal of Advance
Engineering and Research Development, Vol. 5, No.1, pp. 938-947.

4. Introduction to Taguchi Method. 2000 https://www.ee.iitb.ac.in/ apte/CV_PRA_TAGUCHI_IN TRO.htm, 26 August : 1-3.

5. Ravi Kumar, D., Santosh Anand, and Shanthi Raju. 2015 "Optimisation of TMT Process by Taguchi Methodology", Journal of Material Science and Mechanical Engineering, Vol.2, No.12, pp. 44-47.

6. Roy, N.K., and Sandhwar, R.R. 2015. "Study on behavior of MS, CTD and TMT bars", International Journal of Innovative Research in Science, Engineering and Technology, V o 1 . 4, N o . 10, pp. 9813-9817. doi : 10.15680 /IJIRSET.2015.0410070

7. Roy., and Ranjit K. 2001. Design of Experiment Using Taguchi Approach. First Edition, John Wiley and Sons. Srinivas Athreya, and Venkatesh Y.D. 2012. "Application of Taguchi Method for Optimization of Process

8. Parameters In Improving the Surface Roughness of Lathe Facing Operation", International Refereed Journal of Engineering and Science, Vol.1, No. 3, pp. 13-19.

9. Taguchi, G., and Konishi S. 1987. Taguchi Methods, orthogonal arrays and linear graphs, tools for quality American Supplier Institute: pp. 8-35. 